\title{
Representações da leitura em documentos oficiais: discursos sobre a leitura no ensino de Língua Portuguesa
}

DOI: http://dx.doi.org/10.21165/el.v48i3.2204

\section{Luana Alves Luterman'}

\section{Resumo}

Esta pesquisa objetiva analisar e depreender quais são as representações da prática de leitura privilegiadas institucionalmente, ao verificar como se concebe a leitura no ensino de língua materna/portuguesa em documentos oficiais como a LDBen (1996), as Orientações Curriculares para o Ensino Médio - OCEM (BRASIL, 2006) e a Base Nacional Comum Curricular - BNCC (BRASIL, 2018). Será considerada a dimensão discursiva que engendra os documentos oficiais para verificar que projeções de operacionalização das práticas de ensino de língua portuguesa fomentam, orientam, regulam e interditam práticas de leitura. A metodologia baseia-se numa pesquisa quantitativa e qualitativa, apoiada em princípios da Análise do Discurso francesa (FOUCAULT, 2008a; 2008b; 1999a; 1999b; CHARTIER, 2002; COURTINE, 2009) com corpus de enunciados coletado via arquivo digital e/ou impresso, proveniente de sites diversos, do governo federal, constituídos dos documentos citados.

Palavras-chave: língua portuguesa; ensino; leitura.

1 Universidade Estadual de Goiás (UEG), Goiás, Brasil; luanaluterman@yahoo.com.br; https://orcid.org/0000-0001-6491-4045 


\title{
Representations of reading in official documents: discourses on reading in Portuguese language teaching
}

\begin{abstract}
This research aims to analyze and understand the representations of the reading practice institutionally privileged, when verifying how to conceive reading in the teaching of mother language/Portuguese in official documents such as LDBen (1996), the Orientações Curriculares para o Ensino Médio - OCEM (BRAZIL, 2006) and the Base Nacional Comum Curricular - BNCC (BRAZIL, 2018). It will be considered the discursive dimension that forms the official documents to verify that projections of operationalization of the teaching practices of Portuguese language foment, guide, regulate and interdict reading practices. The methodology is based on a quantitative and qualitative research, based on the principles of the French Discourse Analysis (FOUCAULT, 2008a; 2008b; 1999a; 1999b; CHARTIER, 2002; COURTINE, 2009) with corpus of statements collected by digital and/ or printed file, from various websites, from the federal government, consisting of the cited documents.
\end{abstract}

Keywords: Portuguese language; teaching; reading.

\section{Introdução}

No decorrer dos anos, pesquisadores especialistas em áreas específicas de licenciaturas, como Letras e Linguística, são convocados para a elaboração de documentos norteadores da educação nacional. Esses materiais pretendem especificar necessidades triviais que devem interseccionar os currículos das escolas brasileiras de educação básica.

Nossa pesquisa investiga alguns desses instrumentos didáticos, vinculados ao Ministério da Educação (MEC), especificamente em relação às orientações sobre as práticas de leitura no Ensino Médio: LDBen (1996), as Orientações Curriculares para o Ensino Médio - OCEM (BRASIL, 2006) e a Base Nacional Comum Curricular - BNCC (BRASIL, 2018). Tencionamos, neste artigo, apresentar os dados quantitativos coletados por meio do número de ocorrências da palavra leitura nos documentos oficiais mencionados. Posteriormente, analisaremos em que contextos enunciativos esse vocábulo leitura emerge, o que se afirma sobre essa prática e como ela é enunciada com vistas a seu fomento ou interdição.

Quanto à fundamentação teórica, para refletir a respeito das concepções sobre leitura, objetos de nossa investigação, mobilizamos a História Cultural, ao refletir sobre representações simbólicas de determinados grupos ou comunidades que determinam a permanência e/ou a recusa de certas práticas devido à identidade desses grupos e à força de seus poderes (CHARTIER, 2002). 
Para refletir a respeito das variadas conceituações e aplicações da leitura nos documentos oficiais, projetadas para as aulas de língua portuguesa no ensino médio, mobilizamos o aporte teórico-metodológico da Análise do Discurso de linha francesa.

O método arqueológico foucaultiano (FOUCAULT, 2008a, 1999a) baseia a escavação que fazemos de materiais oficiais (oriundos do MEC), voltados para o ensino médio, que versam sobre a leitura, sua conceituação, sua importância e as estratégias de sua efetivação. O método genealógico foucaultiano (FOUCAULT, 2008b, 1999b) contribui para a interpretação e análise dos dados, que aparecem permeados de poderes por meio dos saberes que os engendram: poderes científicos dos pesquisadores especialistas das áreas de formação dos documentos oficiais; poderes políticos particulares, provenientes dos interesses neoliberais - competição dada pelo "livre mercado intelectual" - de formação discente; poderes pedagógicos das autoridades escolares - secretarias de educação, tutores, diretores, coordenadores, professores.

Para compreender a relativa estabilidade de enunciados sobre leitura em condições sóciohistóricas de produção específicas, verificaremos, pela sequência discursiva de referência - a emergência de formulações intradiscursivas sobre a leitura - o funcionamento da memória discursiva por meio da regularidade de certos enunciados, de modo a produzir a existência do acontecimento (COURTINE, 2009) nos documentos oficiais que norteiam a leitura no ensino médio.

\section{Ocorrências do vocábulo leitura nos documentos oficiais nacionais}

Como apoio nodal de nossa metodologia para a investigação do modo como se concebe a leitura nos documentos oficiais do MEC, selecionamos o enunciado leitura. Nele, buscamos a formação discursiva de referência (FDR), isto é, "a sequencialização das formulações no intradiscurso da sequência discursiva de referência [que] se realiza sob a dependência do processo discursivo da formação discursiva que a domina" (COURTINE, 2009, p. 109). O sujeito universal, ainda que produtor de dizeres com valores estabilizados hierarquicamente, pré-construídos, como é o caso dos documentos oficiais, prescreve métodos para atender institucionalmente políticas educacionais. Dessa forma, um saber singular é inscrito numa rede de outros enunciados coerentes quanto ao aspecto identitário, semelhante no processo enunciativo, o que demarca uma série regular e pretende homogeneizar os sujeitos por meio do caráter temático repetível.

Nossa metodologia de pesquisa inicialmente envolve um levantamento quantitativo de dados para consultar a recorrência do tema leitura e suas paráfrases, seu caráter temático repetível - ainda que irrompam reformulações e, quem sabe, ressignificações contraditórias - nos documentos oficiais selecionados: 
Tabela 1. Ocorrência do vocábulo leitura na LDB (BRASIL, 1996), na OCEM (BRASIL, 2006) e na BNCC do ensino médio (no prelo, publicada em abr. 2018 - BRASIL, 2018)

\begin{tabular}{|c|c|}
\hline Documento oficial & $\begin{array}{l}\text { Número de } \\
\text { registros }\end{array}$ \\
\hline Lei de Diretrizes e Bases da Educação Nacional (LDB) - Lei n 9394/96 & zero \\
\hline $\begin{array}{l}\text { Orientações Curriculares para o Ensino Médio (OCEM) - Brasil, 2006- } \\
\text { Linguagens, Códigos e suas Tecnologias - Conhecimentos de Língua } \\
\text { Portuguesa }\end{array}$ & 18 \\
\hline $\begin{array}{l}\text { Orientações Curriculares para o Ensino Médio (OCEM, 2006) - } \\
\text { Linguagens, Códigos e suas Tecnologias - Conhecimentos de Literatura }\end{array}$ & 144 \\
\hline $\begin{array}{l}\text { Base Nacional Comum Curricular (BNCC) - Brasil, } 2018 \text { - versão } \\
\text { preliminar divulgada para apreciação prevista para vigorar no ensino } \\
\text { médio, com a aprovação até } 2019 \text { pelo Conselho Nacional de Educação } \\
\text { - CNE) } \\
\text { Tópicos: * A etapa do ensino médio e O Ensino Médio no contexto da } \\
\text { Educação Básica }\end{array}$ & zero \\
\hline $\begin{array}{l}\text { Base Nacional Comum Curricular (BNCC) - Brasil, } 2018 \\
\text { Tópico: * A BNCC do Ensino Médio }\end{array}$ & zero \\
\hline $\begin{array}{l}\text { Base Nacional Comum Curricular (BNCC) - Brasil, } 2018 \\
\text { Tópico: * Currículos: BNCC e itinerários }\end{array}$ & 1 \\
\hline $\begin{array}{l}\text { Base Nacional Comum Curricular (BNCC) - Brasil, } 2018 \\
\text { Tópico: * A área de Linguagens e suas Tecnologias }\end{array}$ & 2 \\
\hline $\begin{array}{l}\text { Base Nacional Comum Curricular (BNCC) - Brasil, } 2018 \\
\text { Tópicos: * Competências específicas de Linguagens e suas Tecnologias } \\
\text { para o Ensino Médio; * Linguagens e suas Tecnologias no Ensino Médio: } \\
\text { competências especificas e habilidades; * Língua Portuguesa }\end{array}$ & 2 \\
\hline $\begin{array}{l}\text { Base Nacional Comum Curricular (BNCC) - Brasil, } 2018 \\
\text { Tópico: *Língua Portuguesa no Ensino Médio: campos de atuação social, } \\
\text { competências específicas e habilidades }\end{array}$ & 29 \\
\hline
\end{tabular}

Fonte: Elaboração própria 
Os dados quantitativos, ilustrados na tabela 1, demandam ser analisados também qualitativamente, ou seja, são necessárias as considerações das condições de produção enunciativas que agenciam os discursos sobre as práticas de leitura em cada um dos documentos oficiais elencados. Afinal, "toda produção discursiva que se efetua nas condições determinadas de uma conjuntura movimenta - faz circular - formulações anteriores, já enunciadas" (COURTINE, 2009, p. 104). Para isso, além de ler sumariamente todos os documentos, focalizamos os enunciados que fazem parte, em princípio, de um domínio identitário de memória. Como premissa metodológica, ancoramo-nos em Courtine (2009, p. 103): "a memória irrompe na atualidade do acontecimento".

A memória pauta-se pela descontinuidade histórica - e não pela história serial - como primado metodológico para obliterar uma suposta relação de causa e efeito dada pela cronologia, pela linearidade temporal. Segundo Foucault (2008a, p. 290),

\begin{abstract}
A história serial não focaliza objetos gerais e constituídos por antecipação, como o feudalismo ou o desenvolvimento industrial. A história serial define seu objeto a partir de um conjunto de documentos dos quais ela dispõe [...]. Dito de outra forma, o objeto da história não é mais dado por uma espécie de categorização prévia em períodos, épocas, nações, continentes, formas de cultura.
\end{abstract}

Em detrimento de um zeitgeist, uma categoria sobre um espírito de época que engendraria um sistema único de práticas de subjetivação, agruparemos a sequência discursiva de referência leitura e enunciados com temáticas congêneres provenientes de diferentes documentos oficiais, considerando transformações sociais possibilitadas pelas conjunturas históricas, circunstâncias de enunciação, lugar de enunciação, situação de enunciação e outras variantes externas que circunscrevem o ato enunciativo, materializando-o de modo tão específico. Por isso, aferiremos em que medida há paráfrases temáticas sobre os fomentos das práticas de leitura, ou contradições, apagamentos e interdições, inclusive num mesmo documento oficial, e em comparação com outros, independentemente de ele ter sido concebido antes ou depois.

Iniciaremos a análise dos dados coletados pelo apagamento da temática leitura na LDB (1996) e nas páginas iniciais da BNCC do ensino médio (versão ainda no prelo, pendente de aprovação pelo CNE, mas publicada em abril de 2018). Antes, realizaremos um pequeno preâmbulo sobre a irrupção dos documentos oficiais, que privilegiam como saberes qualificados, hierarquicamente superiores, os seus conteúdos, para destacar sua importância em relação às práticas cotidianas de educação básica.

\title{
Documentos oficiais: genealogia dos saberes qualificados
}

Os documentos oficiais que norteiam a configuração da educação básica brasileira permeiam-se de saberes e poderes que distribuem uma espécie de harmonia social 
na educação básica, algo esperado e solicitado pela própria população. Portanto, a genealogia dos saberes qualificados revestidos de poder que legitimam "o que pode e deve ser dito/feito" nas instituições escolares é prerrogativa para o exercício do poder.

Esses compêndios que pretendem homogeneizar as condutas escolares são emitidos sob uma tecnologia, a do poder soberano. Segundo Foucault (2005), esse regime de governo é autoritário: o rei, numa postura autocrática, decide sobre o direito de vida ("deixar viver") ou de morte ("deixar morrer") dos súditos governados por esse sistema. Já nos séculos XVII e XVIII, os juristas consideram os impasses do sistema de poder soberano, que tornam assimétricas as relações entre os cidadãos. No século XIX, o poder se transforma, mesmo que ainda domine a vida dos indivíduos: a diferença é que prevalece a vida, que recebe um cuidado especializado, repleto de traços que estigmatizam o corpo em seu estatuto biológico. Por mais que se modifiquem os exercícios de poder, algo permanece: a disciplina (FOUCAULT, 2008b).

Em vez de controlar a vida individual, a biopolítica governa e vigia populações. Assim como o poder soberano, a biopolítica funciona pela disciplina; contudo essa nova modalidade de poder não funciona pela violência física. Trata-se de um instrumento de poder por vezes considerado tão confortável que é exigido como regência pela própria população, pois garante a proteção da vida, da saúde, da natalidade e da mortalidade, da sexualidade, dispositivos de segurança das populações. Essas regulações são possíveis por normalizações - que naturalizam os poderes, desejados pela própria população em detrimento de normatizações - que remetem à violência, à imposição e ao medo.

Para depreender a circunstância de enunciação da LDB (1996), é preciso compreender que a fragilidade do discurso educacional instala-se no país, de modo que apareça inclusive na população a prática discursiva de paroxismo na educação, o que afeta uma inflação contrária ao sucateamento da instituição escolar. Ocorre, assim, a expectativa da intercessão do discurso jurídico como forma de poder instituir o estabelecimento de regras práticas no funcionamento da educação básica nacional. Essa carência é confirmada em títulos como II e III, respectivamente Dos Princípios e Fins da Educação Nacional (menciona-se, no art. $4^{\circ}$, IX, "garantia de padrões mínimos de qualidade de ensino") e Do Direito à Educação e do Dever de Educar.

A Lei de Diretrizes e Bases (LDB), n. 9394, foi promulgada em 1996, durante o mandato presidencial de Fernando Henrique Cardoso, na gestão de Paulo Renato Souza, Ministro da Educação naquele período. Estabeleceu o dever do Estado em relação à educação escolar, garantindo juridicamente o acesso sem mencionar metodologias de políticas públicas para a gestão do conhecimento. Há, nesse documento, uma discriminação pormenorizada das tarefas governamentais, docentes e discentes; da idade para acesso na Educação Básica (Ensino Fundamental e Médio, também especificações sobre o funcionamento administrativo da Educação Profissional Técnica de Ensino Médio e da 
Educação de Jovens e Adultos - EJA); dos critérios para exercício da docência; além do direito ao ensino, sem instituir ações didático-pedagógicas necessárias a todas as etapas de ensino-aprendizagem.

À União é encaminhada a incumbência de firmar competências e diretrizes para o Ensino Infantil, Fundamental e Médio para balizar uma formação básica homogênea em relação aos direitos civis de todos os estudantes, pulverizados no vasto território nacional brasileiro. Assim, apesar de diferentes os currículos, devido às particularidades das comunidades locais, as competências e diretrizes que permeiam a educação formal devem atravessar toda a metodologia de ensino.

A LDB, em nome da Presidência da República e da Casa Civil, mais particularmente da Subchefia para Assuntos Jurídicos, é elaborada numa situação de enunciação jurídica, que denuncia a ineficácia do sistema educacional básico no Brasil e se dirige à condução da educação básica, por meio de uma estratégia prescritiva de governamentalidade,

[...] o conjunto constituído pelas instituições, os procedimentos, análises e reflexões, os cálculos e as táticas que permitem exercer essa forma bem específica, embora muito complexa, de poder que tem por alvo principal a população, por principal forma de saber a economia política e por instrumento técnico essencial os dispositivos de segurança. Em segundo lugar, por 'governamentalidade' entendo a tendência, a linha de força que, em todo o Ocidente, não parou de conduzir, e desde há muito, para a preeminência desse tipo de poder que podemos chamar de 'governo' sobre todos os outros - soberania, disciplina - e que trouxe, por um lado, o desenvolvimento de toda uma série de aparelhos específicos de governo [e, por outro lado], o desenvolvimento de toda uma série de saberes. (FOUCAULT, 2008b, 143-144).

A LDB, considerada um dever do Estado, valendo-se de seu sistema de normalização jurídica repleto de normas técnicas imbuídas de procedimentos para regulação empreendedora da gestão do aparato físico e funcional das escolas, não interfere na gestão do conhecimento e dos currículos escolares. Por isso, não há registros do vocábulo leitura na legislação.

As Orientações Curriculares para o Ensino Médio (BRASIL, 2006) - Linguagens, Códigos e suas Tecnologias - Conhecimentos de Língua Portuguesa e Linguagens, Códigos e suas Tecnologias - Conhecimentos de Literatura, foram divulgadas no período da presidência da república de Lula, cujo Ministro da Educação era Fernando Haddad. Segundo explica a Apresentação do próprio documento, sua emergência é um produto de discussões 
de sujeitos considerados legítimos² para colaborar com saberes na instituição de um adequado direcionamento curricular no ensino médio: gestores das Secretarias Estaduais de Educação e pesquisadores universitários cujo mote comum de estudo é a pesquisa. Com o apoio da LDB (1996), planeja consolidar a identidade do ensino médio como última etapa escolar da educação básica. Nas OCEM, a palavra leitura aparece 162 vezes.

Vinte e dois anos após as OCEM, em abril de 2018, foi publicada a Base Nacional Comum Curricular (BRASIL, 2018) para o ensino médio, durante o governo do presidente Michel Temer, endossada pelo Ministro da Educação José Mendonça Bezerra Filho. A versão foi divulgada para análise e promulgação do Conselho Nacional de Educação (CNE) e prevê implementação até 2020, após a proposta da Reforma do Ensino Médio, que pretende vigorar até 2019. Na Apresentação do documento (BRASIL, 2018, p.7), há a seguinte exposição:

A presente versão da Base Nacional Comum Curricular (BNCC) completa o trabalho de quatro anos ao longo dos quais o Ministério da Educação (MEC) coordenou o processo de discussão e elaboração da norma que deve orientar os rumos da Educação Básica no País. Este volume reúne a Introdução, a Estrutura e a proposta para o Ensino Médio a ser apreciada e discutida pelo Conselho Nacional de Educação (CNE). Com sua aprovação e homologação, o País estará finalmente dotado de uma Base Nacional Comum para a elaboração dos currículos de todas as etapas da Educação Básica.

O texto remete a um comprometimento árduo e cuidadoso quanto à pesquisa e ao profissionalismo dos autores da BNCC (BRASIL, 2018, p. 7, grifos nossos):("A presente versão da BNCC completa o trabalho de quatro anos [...]. [O] MEC coordenou o processo de discussão e elaboração". A duração do tempo requer a imposição de um atestado de confiabilidade na justeza da confecção da BNCC, revisada cuidadosamente durante quatro anos. Além disso, não se trata de uma política educacional hierárquica, pois a coordenação apaga quaisquer julgamentos autocráticos de um poder soberano: pela biopolítica, o MEC é uma instituição que cuida da vida estudantil e maneja seus instrumentos pedagógicos colaborativos em consonância às participações coletivas, como se fossem acatadas diretamente as contribuições ofertadas em consultas públicas, as quais, de fato, ocorreram. No entanto, a polêmica BNCC desponta em uma ordem sóciohistórica permeada de retaliações e, contraditoriamente, de uma pseudodemocracia, como se fosse unânime a anuência da minuta da BNCC por todo o corpo docente do território nacional.

2 OCEM - Conhecimentos de Língua Portuguesa - consultores: Jane Quintiliano Guimarães Silva, Juliana Alves Assis, Maria de Lourdes Meirelles Matencio; leitores críticos: Ângela Bustus Kleiman, Jaqueline Peixoto Barbosa, Luiz Antônio Marcuschi e Maria da Graça da Costa Val.

OCEM - Conhecimentos de Literatura - consultores: Neide Luzia de Rezende, Maria Zélia Versiani Machado e Enid Yatsuda Frederico; leitores críticos: Lígia Chiappini Moraes Leite e Haquira Osakabe. 
De acordo com a BNCC (BRASIL, 2018), o ensino médio será composto por quatro áreas de conhecimento: Linguagens e suas tecnologias (Língua Portuguesa); Matemática e suas tecnologias; Ciências da Natureza e suas tecnologias; Ciências Humanas e Sociais Aplicadas. A previsão de obrigatoriedade do ensino das áreas de conhecimento nos três anos do ensino médio restringe-se apenas às duas primeiras, Linguagens e suas tecnologias (Língua Portuguesa) e Matemática e suas tecnologias. As instituições escolares podem distribuir como quiserem as outras áreas de conhecimento ao longo dos três anos desta etapa (MARQUES, abr. 2018). Uma das críticas recorrentes à BNCC tem relação com a displicência do MEC com as outras áreas de conhecimento, pois, se competir às redes escolares públicas a oferta, pode ocorrer o apagamento delas, devido ao déficit de professores e à baixa demanda de formação de licenciandos em áreas diferentes de língua portuguesa e matemática, propiciando um desfalque de oportunidades e uma assimetria quanto ao direito isonômico à educação básica, em especial no ensino médio, também ameaçado pela Reforma do Ensino Médio. Retirando compromissos com o profissional graduado em licenciatura, a medida provisória (MP) n 476/2016 contém a cláusula favorável ao notório saber, em que professores sem formação em áreas de licenciatura poderiam atuar na docência técnica profissionalizante.

Tal documento prevê a BNCC, assim como o novo ensino médio - de tempo integral, com 1000 horas anuais, além da formação técnica e profissional dos estudantes. 0 documento é capaz de permitir como premissa a maturidade do estudante secundarista, que seleciona o curso profissionalizante e as áreas de conhecimento. Eis um retrocesso que retoma a marginalização dos estudantes, condenados à subserviência, massa de manobra sem condições de ingressar numa educação básica que ofereça uma educação humanística e crítica, porque o interesse pela formação meramente técnica fomenta a política das terceirizações já prevista pela perda de direitos contidos na Reforma Trabalhista e na Reforma da Previdência, ambas legislações lançadas durante a presidência de Michel Temer.

\section{Apagamento do vocábulo leitura na LDB e em tópicos da BNCC}

Optamos pela análise inicial da seleção de dados semelhantes quanto ao resultado do número de registros. Gostaríamos de compreender como uma legislação completa sobre diretrizes na educação básica (LDB) não contempla o vocábulo leitura e concepções que serviriam para nortear essa etapa do processo escolar. Acrescentamos esse questionamento sobre a tessitura da materialidade textual preliminarmente apresentada pelo MEC sobre a BNCC prevista para ser aplicada no ensino médio.

Para balizar a organização do material de pesquisa coletado, mobilizamos Courtine (2009, p. 99-100, grifos do autor), que desenvolve as veredas metodológicas do fechamento de uma formação discursiva (FD): 
O domínio de saber de uma FD funciona como um princípio de aceitabilidade discursiva para um conjunto de formulações ("o que pode e deve ser dito"), assim como um princípio de exclusão ("determina o que não pode/não deve ser dito"). Ele realiza, assim, o fechamento de uma FD.

Após a varredura lexical, lemos na íntegra os documentos oficiais selecionados para a investigação. Pretendíamos notar a dimensão discursiva que engendra a concretização dos textos sem o vocábulo leitura. No caso específico da LDB (BRASIL, 1996), deduzimos o princípio de exclusão que "determina o que não pode/deve ser dito": não se trata de um documento com a meta de estabelecer parâmetros de ensino/aprendizagem; serve para reafirmar a garantia dos direitos à educação formal básica, além de estabelecer o apoio da União, dos estados e dos municípios. Modelos de educação também configuram a educação básica: esses sistemas são especificados na LDB - educação especial; à distância; profissional e tecnológica; de jovens e adultos e indígena. Ademais, os auxílios financeiros do erário como deveres para o funcionamento adequado das instituições públicas de ensino também são contemplados na LDB, assim como a categorização identitária dos servidores delas, especialmente do corpo docente.

A BNCC (BRASIL, 2018), por sua vez, também contém alguns tópicos sem menção à leitura e suas práticas. Porém, percebemos que isso acontece exatamente nos tópicos que antecedem a área de conhecimento Linguagens e suas tecnologias (Lingua Portuguesa), que se dedica aos procedimentos metodológicos para composição curricular do ensino médio. Notamos, na BNCC, os seguintes métodos pedagógicos dedicados a cada etapa da educação básica:

- Ensino Fundamental: predominância da análise parafrástica, polissêmica e dialógica dos textos.

- Ensino médio: relevância da análise discursiva, crítica, ética, cidadã e autônoma, atuante.

O tópico A etapa do ensino médio, subtópico O Ensino Médio no contexto da Educação Básica, versa a respeito do ensino médio e sua estrutura na conjuntura educacional básica: retoma a formação discursiva do direito dos cidadãos à educação formal básica, pública, que aparece na LDB. Aborda a necessidade de mudança dos preceitos curriculares devido às demandas contemporâneas de urgência quanto à formação tecnológica; às juventudes como taxonomias complexas e múltiplas, imbuídas de atravessamentos sociais e culturais plurais, que exigem da escola novas responsabilidades de formação, de modo a equacionar diferenças e convocar a assumência de constituição de jovens autônomos e críticos. 
O subtópico A BNCC do Ensino Médio, contido também no tópico A etapa do ensino médio, alude às competências gerais e habilidades da educação básica para as áreas de conhecimento já mencionadas, como Linguagens e suas tecnologias (Língua Portuguesa), que demanda a integração de pelo menos duas delas para a promoção da compreensão e transformação da complexidade contextual contemporânea. Apresenta, de modo genérico, que existem aprendizagens consideradas fundamentais e os itinerários formativos para execução em diversas redes e sistemas escolares. Por não objetivar a descrição do caráter didático-pedagógico particular do ensino médio, também apaga a leitura como mote nesse subtópico da BNCC.

\section{Disparidades quantitativas em menções sobre leitura nas próprias OCEM: conhecimentos de língua portuguesa e conhecimentos de literatura}

Previamente à comparação qualitativa entre os documentos oficiais, realizaremos uma análise acerca da variação quantitativa extremamente assimétrica no interior das próprias OCEM (BRASIL, 2006).

No capítulo 1, denominado Linguagens, Códigos e suas Tecnologias - Conhecimentos de Língua Portuguesa, apenas 18 ocorrências para o vocábulo leitura irrompem do documento. Desproporcionalmente, o capítulo 2, intitulado Linguagens, Códigos e suas Tecnologias Conhecimentos de Literatura, registra 144 menções à palavra leitura. Não podemos deixar de considerar tamanha disparidade.

Os Conhecimentos de Língua Portuguesa mencionam que a disciplina de língua portuguesa deve proporcionar aos estudantes o desenvolvimento acurado das habilidades de leitura, escrita, fala e escuta; ao ler textos, ocorre a introspecção, e também o contato com o mundo, gerando no aluno (res)significações subjetivas; a produção do conhecimento ocorre pela leitura e pela sapiência ao fazer circular a leitura; a leitura é uma "ferramenta de empoderamento e inclusão social" (BRASIL, 2006, p. 28); é necessária a exposição a diferentes sistemas de linguagem para a realização crítica de leituras e inclusão em contextos plurais de linguagem; estabelecimento de relações dialógicas entre gêneros textuais de diferentes campos simbólicos, como a diferenciação entre os literários e os não literários para dar vazão à polissemia, aos efeitos múltiplos de sentidos; fornecimento de instrumentos linguísticos para operacionalização da análise linguística ao ler textos, compreendendo tanto os elementos formais, estruturais, internos, quanto os elementos sociopragmáticos e discursivos, condições externas que clivam a existência dos textos; nos eixos organizadores das atividades de língua portuguesa no ensino médio, aparecem recomendações de leitura e compreensão de textos produzidos em esfera pública ou privada, e os lidos em voz alta. 
Os Conhecimentos de Literatura constroem a leitura como uma operação transgressiva, que permite o exercício da liberdade; elege autoridades dessa área do conhecimento para explicar: a) que a leitura é também um ato possível para analfabetos (Magda Soares); b) para dizer que o texto literário é um objeto raro nas aulas, por ser frequentemente substituído por resumos e fragmentos com objetivos utilitários, escolhidos para mera aplicação de análise unilateral de sentido, em detrimento da consideração da subjetividade discente (Regina Zilberman); c) para descrever a marginalização de sujeitos que nunca terão acesso a textos eruditos ou canônicos (Antonio Cândido).

Também discute a polêmica facilidade da leitura considerada popular, "facilmente deglutível" (BRASIL, 2006, p. 59), e a literatura canônica: ambas podem produzir a fruição estética, ainda que a literatura popular seja encarada como mero entretenimento. Faz apologia à leitura silenciosa, que permite um contato mais íntimo com a obra, oferecendo multiplicidades de sentidos e gestos de sensibilidade subjetivos; a (re)leitura, em situações formais, como a aula, e em circunstâncias informais, como o recreio, confronta a si mesmo/ao outro pelos debates e amplia o entendimento do primado cultural fluido, mas, para isso acontecer, é preciso, antes, a efetivação da leitura individual.

A quantidade de remissões à leitura e suas práticas é significativamente menor no capítulo 1. Se 18 registros sobre leitura bastam para nortear as diretrizes curriculares dos conhecimentos de língua portuguesa no ensino médio, refletimos sobre o status dessa modalidade de aprendizagem, ainda pouco considerada em meio aos exercícios de reconhecimento e classificação de unidades linguísticas, algo baseado num condicionamento mnemônico de verificação, por exemplo, de gêneros textuais, mas já definindo as diferenças sociais que atravessam a pluralidade da concretização linguística devido às condições externas ao clivarem sua configuração. Ainda permanecem resquícios do sistema de verificação linguística para classificação, mas agora envolvendo aspectos extralinguísticos para reconhecer como uma categoria de análise pode ser selecionada em detrimento de outra (o gênero discursivo piada, por exemplo, possui efeito cômico; a meta de persuasão e injunção faz parte do gênero discursivo propaganda/publicidade).

No capítulo 2, a concepção de leitura baseia-se em autores consagrados, que são considerados detentores de legitimidade para guiar as práticas de leitura, sobretudo na instituição escolar. Tais representações discursivas são apoios considerados legítimos:

O conceito de representação [...] foi um apoio precioso para [...] as diversas relações que os indivíduos ou os grupos mantêm com o mundo social: primeiramente, as operações de recorte e de classificação que produzem as configurações múltiplas graças às quais a realidade é percebida, construída, representada; em seguida, os signos que visam a fazer reconhecer uma identidade social, a exibir uma maneira própria de estar no mundo, a significar simbolicamente um estatuto, uma ordem, um poder; enfim, as formas institucionalizadas através das quais "representantes" 
encarnam de modo visível, "presentificam", a coerência de uma comunidade, a força de uma identidade, ou a permanência de um poder. (CHARTIER, 2002, p. 169).

Mais uma vez, o funcionamento do poder acontece não pela detenção do poder por um indivíduo, mas pela consideração social de que o conhecimento autoriza certos sujeitos, em detrimento de outros, para ofertar condições de enunciabilidade possíveis por regimes de dizibilidades com valor acadêmico. A representação do que é a boa leitura na instituição escolar é ditada por uma ordem imagética que produz uma realidade palpável, "presentifica" o que efetivamente agencia as articulações textuais literárias dadas como ideais na escola, provocando um efeito de verdade do que é certo e errado como leitura para rendimento epistemológico. Assim funciona o dispositivo pedagógico, assumido pela ciência quando o estado literário da arte é reduzido ao valor didático: mesmo ao valorizar a sensibilidade, a leitura individual e a leitura compartilhada coletivamente, as autoridades acadêmicas controlam a distribuição das obras literárias, atribuindo valor positivo aos cânones, reconhecidos pelo domínio de memória,

[...] constituído por um conjunto de sequências discursivas que preexistem à sdr [sequência discursiva de referência], no sentido em que algumas formulações determináveis na sequencialização intradiscursiva que a sdr realiza ([...] "formulações de referência") entram com formulações que aparecem nas sequências discursivas do domínio de memória, em redes de formulações a partir das quais serão analisados os efeitos que a enunciação de uma sdr determinada produz no interior de um processo discursivo (efeitos de lembranças, de redefinição, de transformação, mas também efeitos de esquecimento, de ruptura, de denegação do já dito). (COURTINE, 2009, p. 111-112).

A maior parte do capítulo 2 é calcada nessa relação dialógica com os autores acadêmicos reconhecidos para, por meio do domínio de memória, alinhar padrões de leitura direcionados como adequados aos adolescentes. Não nos remetemos, portanto, a enunciados adâmicos, originais, formulados pelos autores que emergem nos conhecimentos de literatura das OCEM: a sequência discursiva de referência leitura e congêneres inscreve-se no patamar intradiscursivo do documento oficial por meio de um retorno a sequências discursivas já ditas, que impõem o que é literatura de consumo e o que é literatura canônica. Ao resistirem às leituras canônicas e acessarem as obras literárias de entretenimento, ainda que façam isso fora do lócus escolar, os adolescentes retomam o domínio de memória da leitura autorizada no meio acadêmico para instituir o poder pelo efeito de ressignificação da leitura.

Mesmo que haja a incorporação de textos provenientes de gêneros textuais populares, como hip-hop, quadrinhos e cordel, a abordagem é analógica e se dispõe para "discutir valores estéticos", o que nem sempre respeita subjetividades. Eis aí uma "pluralidade 
contraditória", caracterizada "pela variação sistemática das CP [condições de produção] das sequências discursivas no plano de caracterização das CF [condições de formação] (variações de sujeito de enunciação, de situação de enunciação, de relações de lugares, de conjuntura..." (COURTINE, 2009, p. 110). Sob o gesto de leitura dos adolescentes, conforme as próprias OCEM registram, há um deslocamento da imposição curricular escolar e da leitura obrigatória, pois a preferência de leituras significa liberdade e, muitas vezes, identificação com as condições sócio-históricas contemporâneas.

Assim sendo, a valoração pejorativa depende do sujeito de enunciação, da função exercida, do ambiente de emergência do dizer e de todo o domínio de memória que produz um efeito de verdade sobre o que pode e deve ser lido no contexto escolar. Como a vontade de verdade situa-se principalmente na estética da arte literária e no valor rastreado pelos autorizados em dizer o que pode produzir fruição adequada em favor da sensibilidade e humanização discente, é nos conhecimentos de literatura que irrompem mais pesquisadores literários legitimados academicamente e mais remissões à leitura e suas práticas.

No entanto, percebemos a história como monumento, mosaico de dispersões enunciativas em que podem ser localizadas certas regularidades: a unidade das escolhas anárquicas inseridas na literatura popular como identidade dos estudantes adolescentes tenta ser interditada pelas autoridades que legitimam os cânones. Por outro lado, percebemos na história regularidades como a Bibliothèque bleue, livros de capa azul (CHARTIER, 1998), obras populares na França, que vencem o apagamento da cultura letrada às classes marginalizadas socialmente. São reedições de obras clássicas - estas tradicionalmente lidas pela classe burguesa -, destinadas à classe popular devido à facilidade de compreensão graças ao trabalho linguístico de acessibilidade para alcance mais amplo.

\section{Alusões à leitura e suas práticas em diferentes representações nas OCEM e na BNCC do ensino médio}

Há uma notável diferença entre a quantidade de referências à leitura e suas práticas nas OCEM (principalmente nos Conhecimentos de Literatura) e na BNCC do Ensino Médio. Como já vimos, nas OCEM, o capítulo 1, Linguagens, Códigos e suas Tecnologias - Conhecimentos de Língua Portuguesa, contém 18 ocorrências para o vocábulo leitura. 0 capítulo 2, Linguagens, Códigos e suas Tecnologias - Conhecimentos de Literatura, registra 144 menções à palavra leitura.

A BNCC, no tópico Currículos: BNCC e itinerários, alude à leitura apenas uma vez, quando menciona modos de articulação das áreas do conhecimento - "Clubes: agrupamentos de estudantes livremente associados que partilham de gostos e opiniões comuns (leitura, conservação ambiental, desportivo, cineclube, fã-clube, fandom etc.)." (BRASIL, 
2018, p. 472). O tópico A área de Linguagens e suas Tecnologias, que aborda diretamente a área de conhecimento de Língua Portuguesa no ensino médio, remete à leitura em dois momentos: o primeiro, numa nota de rodapé, que explicita o conceito de práticas de multiletramentos, que envolvem adequado conhecimento das variadas técnicas de operacionalização decodificatória, interpretativa e compreensível de leitura e manejo para produção de textos (multiletramentos) em diferentes linguagens, "como as visuais, as sonoras, as verbais e as corporais" (BRASIL, 2018, p. 478); o segundo cita mídias de comunicação como rádio, TV e mídia impressa, que limitam a participação pública, o que não acontece com a ampliação das redes de comunicação, pois, por meio das tecnologias digitais de informação e comunicação (TDIC), os leitores podem, também, ser produtores de textos e concordar/confrontar conteúdos em gêneros textuais performativos como vlogs, machinemas, AMVs e outros textos que estimulam a interatividade com os leitores.

A diferença da BNCC em relação às OCEM já aparece nas mobilizações de gêneros textuais contemporâneos, bastante intrínsecos à cultura dos adolescentes e, muitas vezes, desconhecidos por serem extremamente recentes. Leitura é amplamente representada, na BNCC, como uma prática de leitura de obras permeadas pelas TDIC. Por isso, as sequências discursivas são dispersas quando nos referimos à sequência discursiva de referência leitura nos documentos oficiais analisados nesta seção, indicando um processo discursivo contraditório.

A dispersão sistemática das sequências discursivas em torno da sequência discursiva de referência será comandada por formas de repartição combinando as sequências discursivas retidas em domínios de objetos, ou "conjuntos diferenciados de sequências discursivas" a partir dos quais será possível formular a hipótese de que a natureza contraditória do processo discursivo da FDR [formação discursiva de referência], assim como o modo de determinação, poderão ser apreendidos. (COURTINE, 2009, p. 110).

Os domínios de objetos se diferenciam conforme as transformações tecnológicas das práticas discursivas de leitura - na contemporaneidade, é inevitável a seleção de gêneros textuais cotidianos nas práticas de leitura escolares. Acrescenta-se, na BNCC, um domínio de objeto não apenas imbricado na sensibilidade e na humanização discente pelos procedimentos de conscientização das plurais subjetividades e paradoxos sociais; o leitor é convocado a saber ler materialidades diferentes das meramente impressas e manejar produtos textuais repletos de múltiplas funções e linguagens. Como criar projetos didáticos sem que sejam reconhecidos esses gêneros textuais (vlogs ${ }^{3}$, machinemas ${ }^{4}$,

3 Vlogs são compostos por vídeos e blogs, em que sobressai o componente visual, ou seja, o vídeo. Trata-se de um vídeo sobre um assunto selecionado.

4 Machinemas (machinimas) são produções fílmicas que hibridizam interações em tempo real e jogos. Disponível em: https://pt.wikipedia.org/wiki/Machinima. Acesso em: 11 jun. 2018. 
$\mathrm{AMVs}^{5}$, fandoms $\left.s^{6}\right) \ldots$ ? Por meio deles, e dos multiletramentos, as conduções da leitura são representadas de outras maneiras, pois o acesso ao conhecimento demanda uma chave não possuída por todo leitor: letramentos digitais, sagacidade para perceber as acuidades sonoras que simbolizam imagens e palavras nos textos.

O tópico Língua Portuguesa no Ensino Médio: campos de atuação social, competências especificas e habilidades é o mais produtivo em relação à emergência do vocábulo leitura: 29 ocorrências. Nele, são descritas minuciosamente as 7 competências específicas de Língua Portuguesa. Leitura aparece na competência específica 5 porque envolve a leitura para compreensão de aspectos da cultura corporal do movimento, em respeito à diversidade e à democracia (BRASIL, 2018, p. 487).

As outras ocorrências aparecem, em geral, na subseção de Língua Portuguesa para detalhar (o que não faremos aqui, devido à limitação da análise) os campos de atuação social criados para atender aos componentes práticos da linguagem no ensino médio: Campo da vida pessoal - reflexão sobre vivências culturais múltiplas e construção de projetos de vida a partir do conhecimento de si e do outro -; Campo artístico-literário desenvolvimento de fruição estética por meio de textos plurissemióticos -; Campo das práticas de estudo e pesquisa - conhecimento de gêneros e habilidades de leitura para a seleção adequada de recortes de dados voltados à "análise, síntese, problematização, reflexão, problematização e pesquisa" (BRASIL, 2018, p. 496) -; Campo jornalísticomidiático - compreensão crítica dos acontecimentos do cotidiano e do funcionamento parcial dos textos que circulam na mídia, ao perceber as diferenças dos posicionamentos em diferentes suportes e a polêmica, detectando e avaliando diferentes pontos de vista, além de refutar discursos de ódio; Campo de atuação na vida pública - letramento jurídico pelo conhecimento básico de direitos e deveres para debates e propostas de mudança social em prol da democracia. O enunciado Leitura, escuta, produção de textos (orais, escritos, multissemióticos) e análise linguística/semiótica emerge em todos os campos de atuação social, delineando um aspecto de leitura mais amplo e mais exigente que o meramente escrito. Trazer à tona outras representações de leitura é algo recorrente na BNCC. A dedicação às modalidades e técnicas de ensino a serviço do apagamento dos preconceitos e tendências sociais periféricas se sobrepõem inclusive aos conteúdos curriculares de língua portuguesa (uma das polêmicas temáticas que têm rechaçado integralmente o conjunto da BNCC, por priorizar um ensino médio tecnicista e com amplo poder decisório dos jovens estudantes quanto à preferência de disciplinas a serem cursadas).

5 AMV (Anime Music Video) é um clipe que congrega diversos animes, "animações" em japonês, produzidos geralmente por uma legião de fãs. Disponível em: https://pt. wikipedia.org/wiki/Anime. Acesso em: 11 jun. 2018.

6 Fandoms são fãs que se identificam pelos gostos em comum. Eles fazem parte de uma rede virtual, mas alguns grupos marcam encontros reais para se conhecerem fora do universo digital. Disponível em: https://pt.wikipedia.org/wiki/Fandom. Acesso em: 11 jun. 2018. 
O investimento pedagógico nos documentos oficiais é diferente. Em cada documento oficial, a concepção de leitura possui referentes e imagens que se inter-relacionam tão intimamente que a coisa, leitura, funde-se com seus próprios conceitos. É impossível conhecer a coisa em sua forma absoluta, em sua essência, "a história da ordem das coisas seria a história do Mesmo - daquilo que, para uma cultura, é ao mesmo tempo disperso e aparentado, a ser portanto distinguido por marcas e recolhido em identidades" (FOUCAULT, 1999, p. 15). As condições históricas e culturais do contexto da BNCC granulam ainda mais especificidades para as leituras em TDIC, concebendo a exibição de um referente, que é a leitura, com outra roupagem, constituída de imagens que possibilitam outra variável concreta, dada pela autoridade oficial privilegiada institucionalmente, endossada pelo Ministério da Educação (MEC).

As sugestões de educação escolar de Língua Portuguesa aparecem como modelos ideais de transformação crítica e cidadã da juventude brasileira, algo esperado desde a LDB, que aparece tanto nas OCEM quanto na BNCC como projeto para o aluno concluinte do ensino médio: que o estudante tenha condições de alcançar estudos mais complexos; de ingressar ao universo profissional e ao aprimoramento, com autonomia; de atuar ética e responsavelmente na sociedade. Para isso, é preciso formar leitores capacitados para compreensão da realidade diversa de sua inserção social. Ao cotejarmos a BNCC e as OCEM no quesito leitura, situamos as diferenças nas maneiras de representação da leitura. Os "diferentes universos multissemióticos" (BRASIL, 2006, p.18) aparecem como necessidade de abordagem nas OCEM, mas o repertório e os protocolos de leitura de gêneros textuais contemporâneos não são evidenciados, muito menos explorados, nominalmente, com propostas metodológicas, como na BNCC. A integração curricular, em detrimento da fragmentação disciplinar, permite traçar a língua portuguesa como área de conhecimento que agrega outras áreas de conhecimento, conforme a BNCC (BRASIL, 2018).

\section{Considerações finais}

Percebemos a amplitude das propostas tanto de leitura estrutural dos gêneros textuais contemporâneos quanto a mobilização deles para o estabelecimento do protagonismo juvenil, em nome da autonomia, "com a promoção de uma educação integral e desenvolvimento pleno dos estudantes, voltada ao acolhimento com respeito às diferenças e sem discriminação e preconceitos" (BRASIL, 2018, p. 5). Como vimos, a LDB (BRASIL, 1996) não versa sobre a leitura, porque não empreende caminhos metodológicos para cumprimento das diretrizes curriculares; porém, a legislação, conforme sua biopolítica jurídica, funciona disciplinarmente em forma de biopoder, função orgânica social capaz de ser exigida para nortear um sistema básico a ser efetivado em âmbito nacional.

Ainda que a BNCC não possua uma seção específica sobre Literatura como área de conhecimento e suas tecnologias, as nuances dessa arte aparecem fluidas, num mosaico 
de propostas híbridas de (re)conhecimento, descrição, interpretação multiletrada das linguagens (sonoras, visuais, tridimensionais, enfım, multimodais). A representação de leitura, embora seja registrada com esse vocábulo apenas 34 vezes, não reflete um deslocamento das práticas de leitura do ensino médio como protocolos desprezados. As 162 vezes em que aparece o vocábulo leitura nas OCEM não significam maior relevo ao estatuto de formação crítica, pois ambas as propostas desejam, na área de conhecimento Língua Portuguesa, a sensibilidade pela fruição estética aprimorada pela leitura.

Percebemos que a conceituação de leitura nos documentos oficiais analisados é líquida, pois nas OCEM - Conhecimentos de Língua Portuguesa a leitura é apresentada como conceituação de texto escrito em múltiplas dimensões; já nas OCEM - Conhecimentos de Literatura, a leitura é apresentada como fruição estética, fator de humanização; e a BNCC direciona as práticas de leitura para atuação e protagonismo social a partir de gêneros discursivos intersemióticos, por meio do suporte das novas Tecnologias Digitais de Informação e Comunicação (TDIC).

Percebemos também, na BNCC, uma diluição das estratégias de leitura dos cânones literários, que apareciam nas OCEM. Tal apagamento parece ser um olhar sobre os programas de leitura escolar oposto aos trabalhos de incentivo à leitura de obras literárias, sejam elas canônicas ou não.

É preciso temer, na BNCC, o utilitarismo da língua portuguesa em favor do ensino técnico, sem relação com outras disciplinas (excluídas pela Reforma do Ensino Médio, ao oferecer autonomia de escolha de áreas de conhecimento pelos estudantes). O entrave é a missão da língua portuguesa como ato redentor da salvação em detrimento das trevas da ignorância, da ausência crítica. A tônica da BNCC, em relação às Linguagens e suas Tecnologias, privilegia os gêneros discursivos, em detrimento de outros conteúdos curriculares fundamentais. Funciona como se conteúdos curriculares atrelados aos gêneros discursivos multimodais não fossem necessários aos multiletramentos, em favor da operacionalização da cidadania, da humanização e da sensibilidade, fatores estes que atravessam todos os documentos oficiais analisados nesta investigação.

\section{REFERÊNCIAS}

BRASIL. Ministério da Educação. Base Nacional Curricular Comum: educação é a base. Ensino médio. Brasília: MEC/SEB/CNE, 2018. Disponível em: http://basenacionalcomum. mec.gov.br/wpcontent/uploads/2018/02/bncc-20dez-site.pdf. Acesso em: 28 abr. 2018.

BRASIL. Ministério da Educação. Orientações curriculares para o ensino médio: linguagens, códigos e suas tecnologias. Brasília: MEC, Secretaria da Educação Básica, 2006. Disponível em: http://portal.mec.gov.br/seb/arquivos/pdf/book_volume_01_internet.pdf. Acesso em: 22 jun. 2018. 
BRASIL. Ministério da Educação. Lei de Diretrizes e Bases da Educação Nacional. Lei n. 9.394/96. Brasília: MEC, Secretaria da Educação Básica, 1996. Disponível em: http:// www.planalto.gov.br/ccivil_03/Leis/L9394.htm. Acesso em: 20 jun. 2018.

CHARTIER, R. A aventura do livro: do leitor ao navegador. Conversações com Jean Lebrun. 1. reimp. Tradução Reginaldo Carmello Corrêa de Moraes. São Paulo: Imprensa Oficial do Estado de São Paulo/Editora UNESP, 1998.

CHARTIER, R. À beira da falésia: a história entre certezas e inquietude. Tradução Patrícia Chittoni Ramos. Porto Alegre: Ed. Universidade/UFRGS, 2002.

COURTINE, J.-J. Análise do discurso político: o discurso comunista endereçado aos cristãos. Tradução Christina de Campos Velho Birck et al. São Carlos: EDUFSCar, 2009.

FOUCAULT, M. Retornar à História. In: FOUCAULT, M.; MOTTA, M. B. (org.). Arqueologia das ciências e história dos sistemas de pensamento. 2. ed. Tradução Elisa Monteiro. Rio de Janeiro: Forense Universitária, 2008a. p. 282-295. (Coleção Ditos e Escritos II).

FOUCAULT, M. As palavras e as coisas: uma arqueologia das ciências humanas. Tradução Salma Tannus Muchail. 8. ed. São Paulo: Martins Fontes, 1999a. (Coleção tópicos).

FOUCAULT, M. Em defesa da sociedade: curso no Collège de France (1975-1976). Tradução Maria Ermantina Galvão. São Paulo: Martins Fontes, 1999b. (Coleção Tópicos).

FOUCAULT, M. Segurança, Território, População. Curso no Collège de France (1977-1978). Tradução Eduardo Brandão. São Paulo: Martins Fontes, 2008b.

MARQUES, M. Base Nacional Curricular (BNCC) do ensino médio é entregue pelo MEC: veja o documento. 3 abr. 2018. Disponível em: https://g1.globo.com/educacao/noticia/ base-nacional-curricular-do-ensino-medio-e-entregue-pelo-mec-veja-o-documento. ghtml. Acesso em: 21 abr. 2018. 